\title{
Preference Responses and Tolerances of the Troglobitic Carabid Beetle, Rhadine subterranea
}

\author{
By Robert W. Mitchell ${ }^{1)}$ \\ With plates 91 (1)-96 (6)
}

\section{Introduction}

The purpose of this research was to determine the preference responses and tolerances of the troglobitic carabid bettle Rhadine subterranea to light, temperature, and relative humidity.

It is somewhat surprising that rather few intensive studies have been made of the responses of cavernicoles to physical factors of the environment. This is especially so since the stability of such physical factors as light, temperature, and relative humidity in caves is matched by few, if any, other environments. Perhaps this stability itself has been the major reason why many researchers have not been attracted to such studies; it is all too easy to assume that troglobites are stenothermal, stenohygrobic, photonegative, and have preferences for saturated atmospheres, narrow temperature preferenda closely corresponding to their cave temperatures, etc.

It is necessary only to examine the summary information provided by Vandel (1964) to appreciate the paucity of data bearing on these phenomena. Although there have been several excellent studies made of various cavernicoles, both terrestrial and aquatic, the data which have been gathered to date are not sufficient to support any general conclusions.

The population of Rhadine subterranea which I studied inhabits Beck's Ranch Cave in southern Williamson Co., Texas. More detailed information on this beetle, the genus Rhadine, and Beck's Ranch Cave may be found in Ball (1960), Barr (1960a), Barr and Lawrence (1960), Bolivar y Pieltain and Hendricks (1964), Mitchell (1968a and 1968b), Reddell (1963 and 1966), and Van Dyke (1918).

1) Department of Biology, Texas Technological College, Lubbock, Texas 79409. 


\section{Materials and Methods}

\section{Preference Studies}

\section{Light Preference Experiments}

For these experiments, alternative boxes of the design shown in Fig. 1 were constructed. Because of the complexity of the design and the limitations imposed by available lighting equipment, only ten of these boxes were built. The walls of the boxes were made of transparent Plexiglas, so it was necessary to set the baffles into the walls to prevent light transmission through the Plexiglas into the dark side. The baffles were not set into the floor since the silt used as a substrate prevented light entering the Plexiglas bottom. The "dark" side of each box was made opaque by painting its exterior black. The entire exterior of the box was then painted white to minimize differential heating.

Each box was checked for light tightness by placing a piece of Panatomic $\mathrm{X}$ film in the dark side and exposing the closed box under a No. 2 photoflood lamp for 15 minutes. The film remained unexposed.

Two 30 watt florescent light tubes were suspended over the boxes resulting in an illumination of about 200 foot candles measured at the substrate level and through the Plexiglas cover of the lid.

One box was used to determine if differential heating was occurring between light and dark sides. A hole was drilled in each end of this box just above the level of the silt substrate, and a thermometer was inserted tightly into each hole. An experimental run was simulated, and no measurable difference between the temperatures of each side was noted.

Repeated experiments were conducted to give a sample size of 48 beetles. Observations were made at ten minute intervals for two hours. The center baffle divided the box equally and was used as the boundary between light and dark sides for recording purposes. If a beetle could not be seen through the transparent part of the lid, the trapdoor was removed to check for its presence in that small area between the center baffle and the baffle on the light side. Beetles seen here were recorded as present on the light side although they occurred in an area of reduced brightness. Beetles were introducted into the boxes by removing the trapdoor and dropping them onto the silt near the free end of the center baffle. Each box contained only a single beetle.

\section{Temperature Preference Experiments}

The apparatus used in these experiments (Fig. 2) consisted of an insulated test chamber with a cold water bath at one end and a hot water bath at the other to establish a temperature gradient within the chamber. An aluminum 
channel $3 \mathrm{~mm}$ thick with inside measurements of $34 \mathrm{~mm} \times 56 \mathrm{~mm}$ made up the bottom and walls of the chamber. The Plexiglas lid enclosed a dead air space to aid in insulation. The chamber was closed on each end by pieces of Plexiglas which were an integral part of the lid and which fitted precisely into the aluminum channel. The lid was sealed to the channel with petroleum jelly.

Plastic tubes fitted with rubber stoppers passed through the lid at $10 \mathrm{~cm}$ intervals so that thermometers could be inserted for temperature measurement. The bulbs of the thermometers were held slightly $(1 \mathrm{~mm})$ above the substrate. There was a variation among the 13 thermometers of about $1 / 2{ }^{\circ} \mathrm{C}$ when all were used to measure the same temperature.

An insulating strip of polystyrene foam $4 \mathrm{~mm}$ thick which fitted loosely in the chamber was provided as a substrate for the experimental animals. This insulating material was used to minimize temperature differential between substrate and air, a commonly occurring problem in apparatus of this type. No temperature difference was detectable when the bulbs of the thermometers were pressed onto the substrate. Beneath the foam substrate was placed a lining of blotter paper saturated with water from the cave to maintain a saturated atmosphere in the chamber. Water vapor could pass freely from the blotter into the air space of the chamber around the edges and through small holes of the loosely fitting foam substrate. Saturation was evidenced by the condensation of water on the inner surface of the lid beginning immediately on the "hot" side of $19.5^{\circ} \mathrm{C}$ (= cave temperature) and by the fact that there was no apparent change in the amount of this water of condensation once the gradient was stabilized.

The water-bath containers were made of eight-liter metal cans to each of which was soldered an additional bottom which fitted into the channel to provide for efficient heat transfer. The use of eight liters of water, the insulation of the entire apparatus with polystyrene foam, and the circulation of water by means of aeration all aided in maintaining a quite stable temperature gradient. A mixture of salt, ice and water was used to establish the cold end of the gradient. It was possible to lower the temperature in the cold end to $0{ }^{\circ} \mathrm{C}$. By sliding the cold bath container farther from the end of the experimental chamber, other desired cold end temperatures could be established. The hot water bath was heated with a 100 watt aquarium heater. About two hours were required to stabilize a gradient of approximately $30{ }^{\circ} \mathrm{C}$ between extremes.

Data were gathered by recording at intervals the number of beetles present in each of the 12 areas of the chamber delineated by the thermometers. When the experiment was run initially in June, 1964, four groups of 12 female beetles each were tested in a gradient of $3{ }^{\circ} \mathrm{C}$ to $32^{\circ} \mathrm{C}$. Six were introduced into the chamber one-third the distance from the cold end and 
six one-third the distance from the hot end. Observations were made of each group at five minute intervals over a two hour period. To determine if the preference would change after long exposure to the gradient, the first 36 beetles tested were returned to the chamber at the conclusion of that run using the fourth group of 12 beetles. Data were gathered from this group of 48 beetles 18 hours later using 12 observational intervals of five minutes duration. No attempt was made to maintain the original gradient over this 18 hour period. The insulation, however, retarded temperature change, and at the end of 18 hours the gradient was $11^{\circ} \mathrm{C}$ to $23.5^{\circ} \mathrm{C}$.

Control data were gathered in a similar manner in the absence of a gradient.

The temperature preference experiment was repeated in December, 1964, when two groups of 12 female beetles each were tested in a gradient from $3{ }^{\circ} \mathrm{C}$ to $37^{\circ} \mathrm{C}$ using 12 five-minute observational intervals.

\section{Relative Humidity Preference Experiments}

The construction of an apparatus in which a relative humidity gradient may be readily established is quite simple, but the problems of measuring the gradient are considerable.

The gradient chamber (Fig. 3) was constructed of Plexiglas and had a tight fitting lid sealed with petroleum jelly. In the bottom of the chamber were six rectangular glass dishes for holding aqueous solutions of sulfuric acid to establish the gradient. The densities of the solutions used were such that if each solution were to have been placed into a separate, sealed chamber relative humidities of $100 \%, 95 \%, 85 \%, 70 \%, 50 \%$ and $25 \%$ would have been produced. A porous substrate of partly fused polyethylene chips which was $6 \mathrm{~mm}$ thick was placed over the dishes.

An opening, sealable with a Plexiglas insert, was provided in one end of the chamber for introduction of the sensor of a relative humidity meter. Unfortunately, the only available meter proved to be inoperative when an attempt was made to measure the gradient.

Twelve bettles, however, were introduced and observed for about 15 minutes. After 1 and $1 / 2$ hours the beetles were again observed. Although it was obvious that the beetles were responding to the gradient, I decided to discontinue these experiments since the gradient could not be measured.

\section{Tolerance studies}

Because beetles were available from the cave only in limited numbers, and since a constant supply was necessary for other experiments, refined tolerance experiments were not permitted. The use of small sample sizes and termination of experiments before death of all beetles helped in conserving the beetle supply. The usual result was insufficient data to test for statistical 
significance, so the tolerance studies are more indicative than conclusive. Nevertheless, such data are useful for speculation.

\section{Temperature Tolerance Experiments}

The apparatus used in these experiments (Fig. 4) consisted of a polystyrene foam box containing water and housing a partially submerged plastic specimen chamber. The water was warmed with a 100 watt aquarium heater. A tightly fitting foam lid was provided with a Plexiglas window for viewing of the beetles. Aeration of the water bath aided temperature control and maintenance of a saturated atmosphere. Air temperature in the specimen chamber was measured by a thermometer the bulb of which was held about $1 \mathrm{~mm}$ above the bottom of the chamber.

After stabilization at the desired temperature the beetles were introduced into the chamber through a stoppered hole in the lid. The sample size for each experiment was 10 (except in one experiment where it was nine) Temperatures of $30^{\circ} \mathrm{C}$ and $35^{\circ} \mathrm{C}$ and times of one and two hours were used. At the conclusion of each experiment, beetles were removed to separate, labeled boxes at cave temperature. Immediately after removal from the chamber the beetles were examined and were recorded as being "alive" if they exhibited movement of any body part. After one week the beetles were reexamined and recorded as "normal", "abnormal", or dead as explained in the discussion of relative humidity tolerance which follows.

There were two major faults in this apparatus. Occasionally water of condensation would run into the specimen chamber, and at times water from the bath would enter the chamber through the perforations when the chamber was being removed at the conclusion of an experiment. Since heat exchange between beetles and water was more rapid than between beetles and air, the data from such experiments were useless. The second fault was that no insulating substrate was provided in the chamber. The temperature of the water bath was several degrees higher than air temperature in the chamber. The $1 \mathrm{~mm}$ thick plastic bottom of the chamber was in direct contact with the bath, and the beetles were placed directly on this. Thus it is probable that the beetles were exposed to a considerably higher temperature than that measured by the thermometer. This would result in an underestimate of the ability of the beetles to tolerate the cited air temperatures. However, an underestimate provides more significant data than an overestimate since conclusions or speculation about the tolerances tend to be conservative.

\section{Relative Humidity Tolerance Experiments}

The apparatus (Fig. 5) was constructed of Plexiglas and consisted of six chambers built into a single unit which was suspended in a water bath. A tube 
opening through the lid permitted introduction of beetles into a specimen tray suspended above a glass jar containing the solution. During an experiment these tubes were tightly stoppered and the lids were sealed with petroleum jelly.

Distilled water was used to establish a control chamber of $100 \%$ relative humidity. Relative humidities of $90 \%, 75 \%, 50 \%, 25 \%$ and $10 \%$ were established in the other chambers using aqueous of sulfuric acid of densities $1.148,1.230,1.336,1.460$ and 1.580 , respectively. Experiments were not conducted until the day following introduction of the solution to allow ample time for equilibration. Since instrumentation was not available for actual measurement of the relative humidity in each chamber, the stated relative humidities must be regarded as approximations.

Sample sizes of 10 beetles per chamber were used. Two groups were tested, 60 males, then 60 females, both at cave temperature for a duration of four hours. At the conclusion of each experiment the beetles were removed to separate, labeled boxes for subsequent observation. One hour after removal, the beetles were examined to determine the number of immediate survivors. The posterior of each beetle was prodded with a probe, and only those which were capable of moving forward were recorded as "alive". The same procedure was repeated after one week and after four weeks. At these times each beetle was recorded either as "normal", "abnormal", or dead. The criterion for "normality" was the ability to both move and coordinate movement of all six legs. Some beetles which were not dead could not walk, or if they could, did not have use of the metathoracic legs. It was assumed that all deaths resulted from dessication.

\section{Results}

\section{Light Preference Experiments}

Control data were gathered first in the absence of light. Male control data consisted of 283 occurrences on the "light" side and 293 occurrences on the "dark" side, yielding a $\chi^{2}=.174$ and $\mathrm{P}>.50$. Female control data consisted of 287 "light" occurrences and 289 "dark" occurrences, yielding a $\chi^{2}=.007$ and $\mathrm{P}>.90$. These $\mathrm{P}$ values indicated the absence of bias in the box design and permitted comparison of the experimental data to the theoretical expected 1:1 distribution.

Male experimental data consisted of 263 occurrences on the light side and 313 occurrences on the dark side, yielding a $\chi^{2}=4.34$ and $\mathrm{P}<.05$. Female experimental data consisted of 244 light side occurrences and 332 dark occurrences, yielding a $\chi^{2}=6.72$ and $\mathrm{P}<.01$. 


\section{Temperature Preference Experiments}

Fig. 6 shows graphically the number of beetle occurrences in each area of the gradient chamber during control and experimental runs. Graph 1 is the corresponding control frequency for the experimental frequencies in Graphs 2 (June data) and 5 (December data), and Graph 3 is the corresponding control frequency for the experimental frequency in Graph 4 (June data).

Although there are obvious differences between the graphs, appropriately corresponding frequencies were compared statistically. It was not possible to compare the experimental frequency distributions with theoretical expected distributions assuming equal frequency in each area because the control frequencies were biased. It is apparent from Fig. 6, Graphs 1 and 3, that this bias (significant at $\mathrm{P}<.05$ ) resulted from a tendency of the beetles to occur more often near the ends of the chamber than in the middle. It is a common occurrence for captive animals to move about within their enclosure until they are concentrated at its limits.

Statistical analysis, however, is not precluded since contingency table analysis allows the comparison of different frequency distributions without assuming any underlying theoretical distribution. Table 1 shows contingency table tests of the June experimental frequencies and their corresponding control frequencies and of the December frequency distribution and the appropriate frequencies from the June data. In each comparison the differences are highly significant $(\mathrm{P}<.001)$. The latter comparison is not as meaningful as it might be since slightly different gradients were set up in the June and December experiments. However, only qualitative examination is required to appreciate the differences in beetle response at the two different times.

In Experiment 1 about two-thirds of the observations were in areas 2 and 3 representing a temperature range from $7.5^{\circ} \mathrm{C}$ to $13^{\circ} \mathrm{C}$. Although it is not revealed in these numerical data, most of those beetles recorded from area 2 were nearer the $11^{\circ} \mathrm{C}$ boundary than the $7.5^{\circ} \mathrm{C}$ boundary. In Experiment 2 slightly more than one-half of the observations were from area 1 representing a range of $11^{\circ} \mathrm{C}$ to $13^{\circ} \mathrm{C}$. Slightly less than one-half of $1 \%$ of the observations in Experiment 1 were from that section of the chamber exceeding $24.5^{\circ} \mathrm{C}$, and only about $1 \%$ were from the coldest area, $3^{\circ} \mathrm{C}$ to $7.5^{\circ} \mathrm{C}$. Only about $7.4 \%$ of the observations were from that area (area $7,19^{\circ} \mathrm{C}$ to $20.5^{\circ} \mathrm{C}$ ) most closely approximating cave temperature. In Experiment 2 only about $2.8 \%$ of the observations were from that area (area $9,19.5^{\circ} \mathrm{C}$ to $20^{\circ} \mathrm{C}$ ) most closely approximating cave temperature.

Using $20.5^{\circ} \mathrm{C}$ in Experiment 1 and $20^{\circ} \mathrm{C}$ in Experiment 2 as the temperatures nearest cave temperature, it is seen that about $94 \%$ and $95 \%$, respectively, of the observations were from that section of the chamber colder than cave temperature. 
Response to the gradient was immediate. In each of the four groups of beetles introduced during Experiment 1, those introduced into the hot end moved immediately and directly toward the cold end.

The data from Experiment 3 run in December are drastically different from those of Experiment 1 which was run in June. In Experiment 3 only about $3.8 \%$ of the observations were from that temperature range $\left(7^{\circ} \mathrm{C}\right.$ to $14^{\circ} \mathrm{C}$ ) where about two-thirds of the observations in Experiment 1 were made. Two-thirds of the observations in Experiment 3 were recorded in the range from $17.5^{\circ} \mathrm{C}$ to $24^{\circ} \mathrm{C}$, a range from which only about $18 \%$ of the Experiment 1 observations were recorded. In Experiment 3 the total observations were about equally divided between the hot end $\left(>20^{\circ} \mathrm{C}\right)$ and the cold end $\left(<20^{\circ} \mathrm{C}\right)$ while in Experiment 1 the great majority of the observations were from the cold end.

Since there was no change in apparatus or experimental design between June and December, it is apparent that a shift in temperature preference of the beetles occurred during the interval between Experiments 1 and 3. The preference in June was for a temperature much less than cave temperature, and the preference in December approximated that of cave temperature.

\section{Relative humidity preference experiments}

As mentioned previously, this experiment was discontinued because the relative humidity gradient could not be measured. The observations of the 12 beetles which were introduced into the chamber are, however, worthy of mention. During the first 15 minutes after introduction the beetles moved continuously about the entire chamber. There was no apparent immediate response to the gradient either in speed or direction of movement. It is possible that these observations are misleading, however. Since the beetles were introduced shortly after an unsuccessful attempt to measure the relative humidity gradient in the chamber, it is possible that the gradient was disturbed.

When observed again after one and one-half hours, all 12 beetles were motionless above the dish containing the distilled water.

\section{Tolerance Studies}

\section{Temperature tolerance experiments}

Results of these experiments are summarized in Table 2. During exposure to the elevated temperatures the beetles were highly agitated, and most had poorly coordinated movements. Some turned over onto their backs and were unable to right themselves except by seizing a passing beetle with their 
mandibles although they could normally right themselves easily. The temperature shock which occurred when the beetles were moved back to cave temperature at the termination of the experiment immobilized many of the beetles and reduced the speed and coordination of all. It is possible that this shock was more responsible for beetle deaths than the elevated temperature itself.

Since the temperatures measured were air temperatures which were most likely lower than substrate temperature, the results are probably conservative estimates of the ability of the rhadinids to tolerate elevated temperatures.

The beetles from the $30^{\circ} \mathrm{C}$ experiments resumed their hole-digging behavior in the stock boxes subsequent to the experiment, but hole-digging by those beetles from the $35^{\circ} \mathrm{C}$ experiment was greatly retarded.

\section{Relative humidity tolerance experiments}

The results of these experiments are shown in Table 3. After the beetles had been in the chambers for several minutes those at the lower relative humidities became highly agitated. In fact, there was a striking gradation in activity through the successively lower relative humidities.

\section{Discussion}

Preference and tolerance data are essential in attempting to answer some important biospeleological questions. What, if any, relationship exists between the degree of morphological regression of troglobites and their ability to perceive and respond to physical factors of the environment? What are the mechanisms which operate to restrict cavernicoles within their optimal environment? What are the capabilities of cavernicoles for dispersal in the epigeum?

In consideration of the first question, it seems plausible to hypothesize that at least certain kinds of troglobites would not possess as great an ability as would related epigeal species to respond to those physical factors which are variable in the epigeum but which are relatively stable in caves. And, to extend the hypothesis somewhat farther, in a series of related troglobites there should be a negative correlation between ability to respond and morphological regression. I would offer this hypothesis as appropriate only for those troglobites which are physically imprisoned in their subterranean habitats. Such troglobites would be primarily those aquatic species living in subterranean water systems which lack navigable connections with epigeal waters. The maintenance of those mechanisms which permit epigeal animals to perceive environmental variability would seem to be of little 
or no selective advantage to troglobites trapped in a stable environment. In addition, it is possible that in animals, generally, acute response abilities are maintained at a greater energy cost than lesser ones, so that those individuals with the lesser response abilities would be at a selective advantage.

It would seem inappropriate to extend this hypothesis to all cavernicoles, and the reason for this relates to the second question asked at the beginning of this discussion. It is possible that certain kinds of troglobites might retain acute response abilities functioning as mechanisms restricting them to their subterranean environment. Terrestrial troglobites and those aquatic species inhabiting subterranean systems with navigable communications with surface waters certainly have the capability, by virtue of their own motility, of moving into the epigeum. The fact that troglobites are almost never taken in epigeal environments, even those immediately surrounding cave entrances, is good circumstantial evidence that there are, in fact, restrictive mechanisms in operation. It is not enough to propose that troglobites are absent from the epigeum because they die upon entering it. Active mechanisms must exist since selection would rapidly eliminate those individuals entering a hostile environment while favoring those which could perceive and retreat from it.

Behavioral responses to the more obvious environmental variables such as light, temperature, relative humidity, and water and air movement might all function as these active restrictive mechanisms. It is obvious, however, that any one of these would be only partially effective. There would be many times when for any of these physical factors both the cave and the immediate epigeum would be similarly characterized. On the other hand, it would only be an exceptional chance occurrence that both cave and epigeum would be similar in all those physical factors, even the gross ones, that cavernicoles might respond to.

I could, then, propose as a second general hypothesis that terrestrial troglobites and some aquatic ones possess a complex of behavioral responses which operate to restrict them in their cave environment.

The third question asked at the beginning of this discussion relates to cavernicole dispersal. Perhaps it is here important to recall that the tendency to disperse seems to be characteristic of most living organisms. A great variety of morphological, physiological, and behavioral characteristics of many plants and animals suggests that this tendency is of positive selective value, at least on a long term basis. This would permit survival as an old habitat became unsuitable by the colonization of a new, suitable habitat. There is no reason to suspect that cavernicoles lack this tendency to disperse. In fact, there is every reason to suspect that it is present, since, considered on a geological or evolutionary time scale, caves are ephemeral habitats. Although the most important routes for cavernicole dispersal are probably 
subterranean (Barr, 1959), these lack the permanence of the epigeum, so it does not seem unreasonable to expect some epigeal dispersal by some cavernicoles. There are some troglobite distribution records inconsistent with proposed subterranean channels and barriers (Barr, 1960 b; Krekeler, 1959). Possibly the "inconsistencies" are the results of epigeal dispersal.

Although epigeal routes would seem to be difficult for any kind of troglobite, terrestrial species would seem more likely to use them than would aquatic species. First, cave aquatics, would most likely be dependent upon environmental water regardless of the location of dispersal routes. Passive overland transport by larger animals and air currents is important (Maguire, 1963) and cannot be discounted, although for obvious reasons it would seem to be far more important for epigeal than subterranean species. Second, subterranean dispersal routes are unsuitable for terrestrial species when they are water-filled.

The possibility of cavernicole dispersal in the epigeum would seem at first thought to be concerned only with tolerances. Obviously, if troglobites are ever successful in the of epigeal routes, they must be capable of surviving environmental conditions to which they are not exposed in their subterranean environment. But also important are their behavioral responses to physical factors of the environment. If these responses are, in fact, important as mechanisms restricting troglobites to their habitat as I have hypothesized, they must remain at least slightly imperfect if the epigeum is to ever be initially entered.

It might now be hypothesized that behavioral restrictive mechanisms, if they exist, are not absolute but permit entry into the epigeum at those times when the chances for survival would be maximal.

I must here hasten to stress that these suggestions I have made are nothing more at the present than working hypotheses, but any would justify the effort in gathering the data necessary to support or refute it. Many data are needed from many different kinds of troglobites before substantial progress will be made. As always, the most interesting data will no doubt be those which are to the contrary of some previously espoused hypothesis.

The preference and tolerance data I have gathered on Rhadine subterranea will now be examined in terms of the preceeding discussion.

$R$. subterranea responds negatively to light as do perhaps most of the cavernicoles which have been studied. However, this response is not especially pronounced. It is, in fact, impossible to determine the nature of the response by merely observing the beetles' activities in a light gradient. Only the quantitative data from the alternative boxes revealed the negative response. This response would appear to result from a slightly greater rate of movement in lighted areas, and thus would be a kinesis rather than a 
taxis. Since the response is rather weak, it is probable that it does not play a major role in restricting the beetles to the cave. It is possible that even a strong negative response to light would not be a major restrictive mechanism for the simple reason that it would be operative only a part of the time. Neither would any kind of kinetic response seem to be of major importance since too many "mistakes" would be made by the animal during its movements.

The temperature preference data are the most interesting to result from these studies. The shift from a summer preference of a temperature about $10^{\circ} \mathrm{C}$ lower than that of the cave to a winter preference approximating that of cave temperature is a drastic change. Although these preference experiments were run at only two times, June and December, I believe the different results to be entirely a function of season since this was the only apparent variable in these experiments. Response in the temperature gradient was obviously klinotactic since the beetles concentrated rapidly and by direct movements within the preferred zone of the gradient.

Possibly this shift in temperature preference is the primary mechanism restricting the beetles to the cave. A temperature preference which would shift as an inverse function of prevailing temperatures in the epigeum would appear to be a very efficient restrictive mechanism. In addition, a klinotaxis would seem to be the most efficient type of response since the animals would be quickly removed from unfavorable stimuli.

If this shift in temperature is, in fact, real, then the beetles must receive some cue which initiates the shift. Because of the internal stability of the cave, it is difficult to envision such a cue coming directly from the epigeum. Although it is entirely speculation, it is possible that the beetles are cued through their diet. I have already shown that the eggs of cave crickets are a primary food source for these beetles (Mitchell, 1968a). Two cave crickets, Ceuthophilus cunicularis and C.n.sp., live in Beck's Ranch Cave, and although no quantitative data are available, it appears that $C$. cunicularis is a "summer" species while $C$.n. sp. is a "winter" species. Perhaps the rhadinids shift seasonally from feeding on the eggs of one species of cricket to those of the other thus cuing the shift in temperature preference.

Although the relative humidity preference experiment was unsuccessful, the beetles did at least eventually accumulate in the area of lowest saturation deficit. A great reduction in size of the available beetle population was correlated with the obvious loss of water from the substrate which occurred during the summers. For example, in the spring of 1963 as many as 150 beetles could be taken at a single collection in a certain part of the cave while in August of that year only eight individuals could be found during one collection attempt. The drop in available population size was again apparent in the summer of 1964, although it was not as pronounced as in 
the previous year. During the fall the numbers increased, and the returning beetles were the same ones which had disappeared during the summer as evidenced by the reappearance of some individuals marked during the previous spring. In addition, the returning beetles were fully pigmented, so they were not a replacement population of recently emerged individuals. I have assumed that the beetles retreated deeper into crevices inaccessible to collection as the relative humidity decreased, however slightly. If this is so, the rhadinids possess an acute ability to differentiate between saturation and slightly less than this.

Negative response to relative humidities lower than $100 \%$ is possibly operative in restricting the beetles to the cave, although it would seem to suffer from being a kinesis.

The temperature and relative humidity tolerance studies were inconclusive but seem to be indicative. The ability of the beetles to tolerate with no apparent ill effects a two-hour exposure (at $100 \%$ relative humidity) to a temperature exceeding that of their environment by $10^{\circ} \mathrm{C}$ does not seem to qualify them as strict stenotherms. Nor does their ability to tolerate with about $50 \%$ survival a four-hour exposure (at cave temperature) to relative humidities of $50 \%$ and less indicate strict stenohygroby. It is probably reasonable to assume, however, that there would be a rapid decrease in the ability of the beetles to tolerate the effects of elevated temperature and reduced relative humidity when they are combined.

These data seem to admit to the possibility that $R$. subterranea could use an epigeal dispersal route successfully. The most likely time for a beetle to enter the epigeum would be when the epigeum was characterized by darkness, a temperature corresponding to the temperature preferendum of the beetles, and an atmosphere at, or approaching, saturation. The summer temperature preference would appear to be very restrictive during that time of the year when, in view of the tolerance data, chances for survival would be minimal. The winter preference would seem to be less restrictive, permitting the beetles to enter the epigeum at a time when their chances for survival in the epigeum would appear to be maximal. Once in the epigeum the beetle could move about quite readily occasionally seeking refuge in the humid recesses under rocks and in debris. So long as its exposures to lowered relative humidities and rising temperatures were of reasonably short duration, it could probably exist for an extended period in the epigeum.

Novembre 1967

\section{SUMMARY}

Studies were made on the preference responses and tolerances of the troglobitic carabid beetle Rhadine subterranea to light, temperature, and relative humidity. The beetles are weakly photonegative and appear to have a strong preference for atmospheres of low saturation deficit. Both these responses seem to be orthokineses. Th ey 
have a strongly developed temperature sense, and their temperature preferendum shifts seasonally. This response seems to be a klinotaxis. They are neither strongly stenothermal nor stenohygrobic. The preference responses, especially that of temperature, are probably mechanisms tending to restrict the beetles to their habitat. The tolerance data suggest that the epigeum could, at times, be used as a dispersal route.

\section{RÉSUMÉ}

Les préférendums et les limites de tolérance vis-à-vis de la lumière, de la température et de l'humidité relative ont été étudiés chez le Carabique troglobie Rhadine subterranea.

Cet Insecte montre un léger phototaxisme négatif et semple avoir une préférence très marquée pour les atmosphères à léger déficit de saturation. Il possède un sens de la température fortement développé et son thermopréférendum varie suivant les saisons. Cette réponse semble être une clinotaxie. Il n'est ni fortement sténotherme, ni fortement sténohygre. Les préférendums, particulièrement celui à la température, sont probablement un des mécanismes tendant à limiter les Insectes à leur habitat. Les données sur les limites de tolérance permettent de supposer que le domaine épigé peut, quelque fois, être utilisé comme voie de dispersion.

\section{ACKNOWLEDGEMENTS}

I wish to thank Mr. E. O. Beck, owner of Beck's Ranch Cave, for his cooperation and interest in my studies. I am also appreciative of the assistance of Dr. Bassett Maguire, Jr., Dr. Bobbi Lowe, Dr. Michael Menaker, Dr. H. Grey Merriam, Mr. James R. Reddell and Dr. Bert A. Tribbey. I also thank all members of the University of Texas Speleological Society for their continuing cooperation.

Table 1

Contingency table analyses of temperature preference data

June Data

Area of gradient chamber

\begin{tabular}{lrrrrrrrrrrrr} 
& 1 & 2 & 3 & \multicolumn{1}{c}{4} & \multicolumn{1}{c}{5} & 6 & 7 & 8 & 9 & 10 & 11 & 12 \\
\hline Control & 122 & 90 & 85 & 108 & 106 & 59 & 85 & 75 & 74 & 87 & 100 & 161 \\
Exp. 1 & 12 & 405 & 356 & 87 & 82 & 66 & 73 & 38 & 28 & 2 & 3 & 0
\end{tabular}

$\chi^{2} / 11$ d. f. $=830.28, \mathrm{P}<.001$

\begin{tabular}{lrccccccccccr} 
& 1 & 2 & 3 & 4 & 5 & 6 & 7 & 8 & 9 & 10 & 11 & 12 \\
\hline Control & 62 & 55 & 44 & 36 & 48 & 46 & 21 & 24 & 22 & 65 & 66 & 75 \\
Exp. 2 & 300 & 70 & 36 & 31 & 43 & 14 & 15 & 18 & 16 & 22 & 9 & 2
\end{tabular}

$\chi^{2} / 11$ d. f. $=414.52, \mathrm{P}<.001$

\section{December Data}

\begin{tabular}{lrrrrrrrrrrrr} 
& 1 & \multicolumn{1}{c}{2} & \multicolumn{1}{c}{3} & \multicolumn{1}{c}{4} & \multicolumn{1}{c}{5} & 6 & 7 & 8 & 9 & 10 & 11 & 12 \\
\hline Control & 122 & 90 & 85 & 108 & 106 & 59 & 85 & 75 & 74 & 87 & 100 & 161 \\
Exp. 3 & 0 & 4 & 7 & 23 & 28 & 71 & 62 & 61 & 16 & 6 & 6 & 4
\end{tabular}

$\chi^{2} / 11$ d. f. $=306.05, \mathrm{P}<.001$

\begin{tabular}{lrrlllllc} 
& $1+2$ & 3 & 4 & 5 & 6 & 7 & 8 & $9+10+11+12$ \\
\hline Exp. 1 & 417 & 356 & 87 & 82 & 66 & 74 & 38 & 33 \\
Exp. 3 & 4 & 7 & 23 & 28 & 71 & 62 & 61 & 32
\end{tabular}

$\chi^{2} / 7$ d. f. $=456.99, \mathrm{P}<.001$ 
Table 2

Results of temperature tolerance experiments. Criteria used for expression of results are explained in Methods section. Sample size for each experiment was 10 unless otherwise indicated.

\begin{tabular}{|c|c|c|c|}
\hline \multicolumn{4}{|c|}{ Male } \\
\hline Temperature & Duration & $\begin{array}{l}\text { Alive at end } \\
\text { of experiment }\end{array}$ & $\begin{array}{l}\text { Normal at end } \\
\text { of one week }\end{array}$ \\
\hline $30^{\circ} \mathrm{C}$ & $2 \mathrm{hrs}$ & 9 (of 9) & 9 \\
\hline $35^{\circ} \mathrm{C}$ & $1 \mathrm{hr}$ & 7 & 0 \\
\hline $35^{\circ} \mathrm{C}$ & $2 \mathrm{hrs}$ & 0 & 0 \\
\hline \multicolumn{4}{|c|}{ Female } \\
\hline Temperature & Duration & $\begin{array}{l}\text { Alive at end } \\
\text { of experiment }\end{array}$ & $\begin{array}{l}\text { Normal at end } \\
\text { of one week }\end{array}$ \\
\hline $30^{\circ} \mathrm{C}$ & $2 \mathrm{hrs}$ & 10 & 10 \\
\hline $35^{\circ} \mathrm{C}$ & $1 \mathrm{hr}$ & 10 & 6 \\
\hline
\end{tabular}

Table 3

Results of the relative humidity tolerance experiments. Criteria used in expressing results are explained in Methods section. Sample size for each experiment was 10

\begin{tabular}{cccc}
\multicolumn{3}{c}{ Male } \\
$\begin{array}{c}\text { Relative } \\
\text { humidity }\end{array}$ & $\begin{array}{c}\text { "Dead" one hour } \\
\text { after exp. }\end{array}$ & $\begin{array}{c}\text { "Normal" after } \\
\text { one week }\end{array}$ & $\begin{array}{c}\text { "Normal" after } \\
\text { four weeks }\end{array}$ \\
\hline $100 \%$ & 0 & 10 & 10 \\
$90 \%$ & 0 & 10 & 9 \\
$75 \%$ & 0 & 9 & 7 \\
$50 \%$ & 5 & 7 & 5 \\
$25 \%$ & 7 & 5 & 3 \\
$10 \%$ & 9 & 5 & 4 \\
\hline
\end{tabular}

Female

\begin{tabular}{cccc}
$\begin{array}{c}\text { Relative } \\
\text { humidity }\end{array}$ & $\begin{array}{c}\text { "Dead" one hour } \\
\text { after exp. }\end{array}$ & $\begin{array}{c}\text { "Normal" after } \\
\text { one week }\end{array}$ & $\begin{array}{c}\text { "Normal" after } \\
\text { four weeks }\end{array}$ \\
\hline $100 \%$ & 0 & 10 & 10 \\
$90 \%$ & 0 & 10 & 9 \\
$75 \%$ & 1 & 9 & 7 \\
$50 \%$ & 4 & 8 & 5 \\
$25 \%$ & 7 & 7 & 6 \\
$10 \%$ & 9 & 7 & 5 \\
\hline
\end{tabular}




\section{REFERENCES CITED}

BaLl, G. E. (1960) - Carabidae. In Arnett, R. H. (Ed.). The beetles of the United States. Washington, D. C., The Catholic Univ. of America Press.

BARr, T. C. (1959) - New cave beetles (Carabidae, Trechini) from Tennessee and Kentucky. J. Tenn. Acad. Sci., 34: 5-30.

- (1960a) - The cavernicolous beetles of the subgenus Rhadine, genus Agonum (Coleoptera: Carabidae). Am. Midl. Nat., 64 (1): 45-65.

- (1960 b) - Symposium: speciation and raciation in cavernicoles ... Introduction. Am. Midl. Nat., 64 (1): 1 -9.

-, and J. F. Lawrence. (1960) - New cavericolous Agonum (Rhadine) from Texas (Coleoptera: Carabidae). Wasmann J. Biol., 18 (1): 137-145.

Bolivar y Pieltain, C., and J. Hendrichs (1964) - Agoninos cavernicolas nuevos del genero Rhadine de Nuevo Leon, Coahuila y San Luis Potosí (Mexico). Cienca, 23 (1): 5-16.

KreKeler, C. H. (1959) - Dispersal of cavernicolous beetles. Systematic Zool., 8 (3): $119-130$.

MAGUire, B., JR. (1963) - The passive dispersal of small aquatic organisms and their colonization of isolated bodies of water. Ecol. Monographs, 33: $161-185$.

Mitchell, R. W. (1968a) - Food and feeding habits of the troglobitic carabid beetle Rhadine subterranea. Intern. J. of Speleology.,/4.

Mitchell, R. W. (1968b) - Distribution and dispersion of the troglobitic carabid beetle Rhadine subterranea. Intern. J. of Speleology.,/4.

Reddell, J. R. (1963) - The caves of Williamson County. Texas Speleological Survey, 1 (2).

- (1966) - A checklist of the cave fauna of Texas. II. Insecta. Texas J. of Sci. 18 (1): $25-56$.

VANDEL, A. (1964) - Biospeologie, la biologie des animaux cavernicoles. Paris, Gauthier-Villars, 1-619.

VAN DyKe, E. C. (1918) - A new genus and species of cave-dwelling Carabidae (Coleoptera) from the United States. J. New York Entomol. Soc., 26: 179-182.

\section{EXPLANATIONS OF PLATES 91 (1)-96(6)}

Plate 91 (1): Light - dark box

Plate 92 (2): Temperature preference apparatus

Plate 93 (3): Relative humidity preference apparatus

Plate 94 (4): Temperature tolerance apparatus

Plate 95 (5): Relative humidity tolerance apparatus

Plate 96 (6): Frequencies of beetle occurrences within the areas of the temperature gradient chamber. Ordinate - frequency. abscissa - number of area (first row) $\&$ temperatures in ${ }^{\circ} \mathrm{C}$. (second row). 


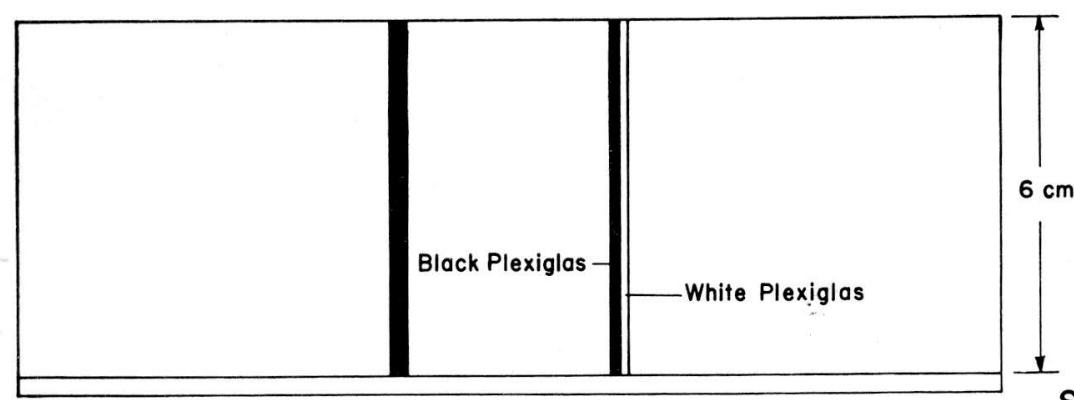

Side view
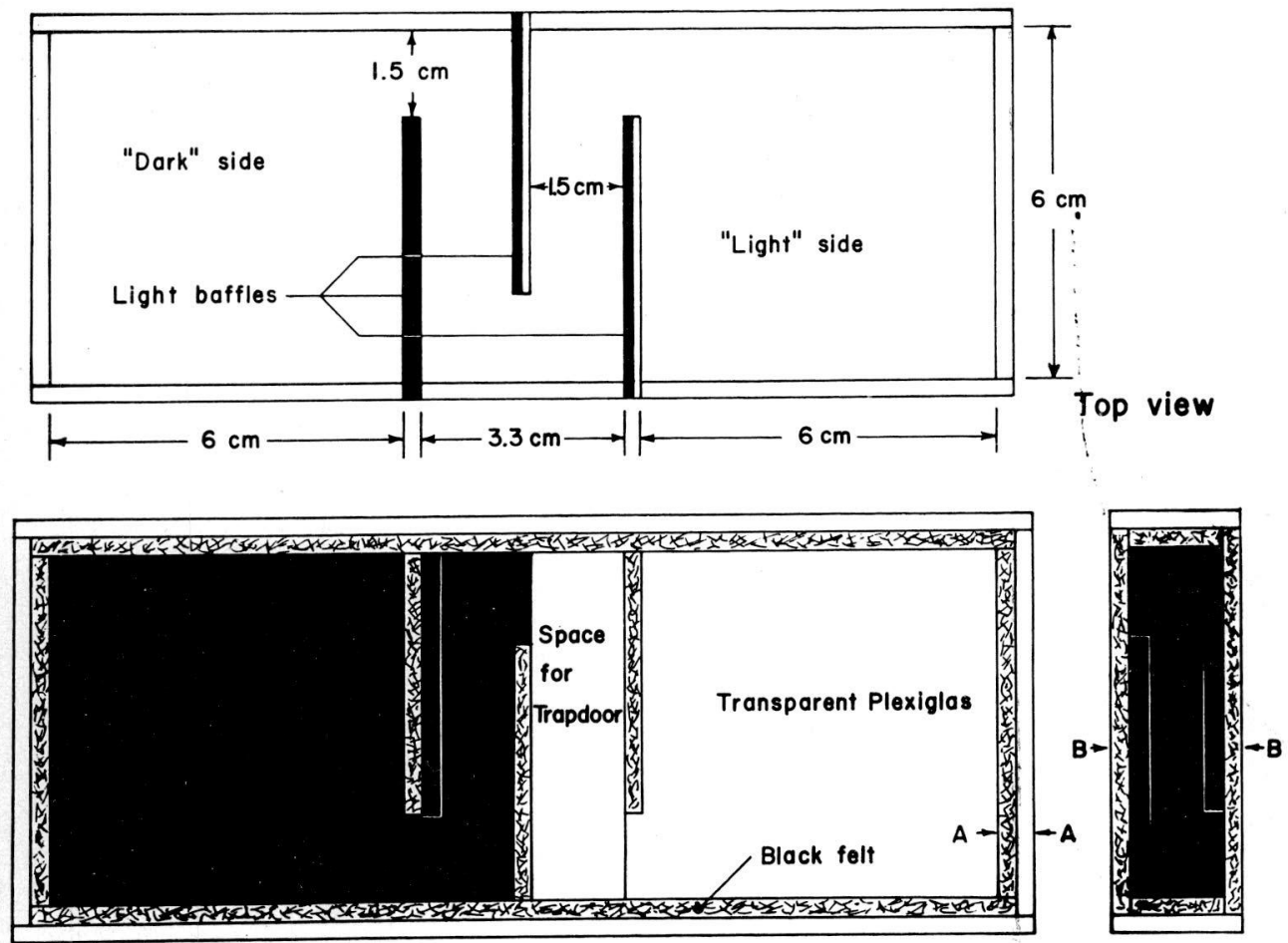

\section{Lid}

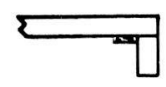

$$
\text { A-A }
$$

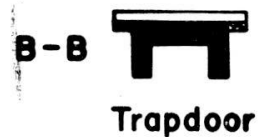



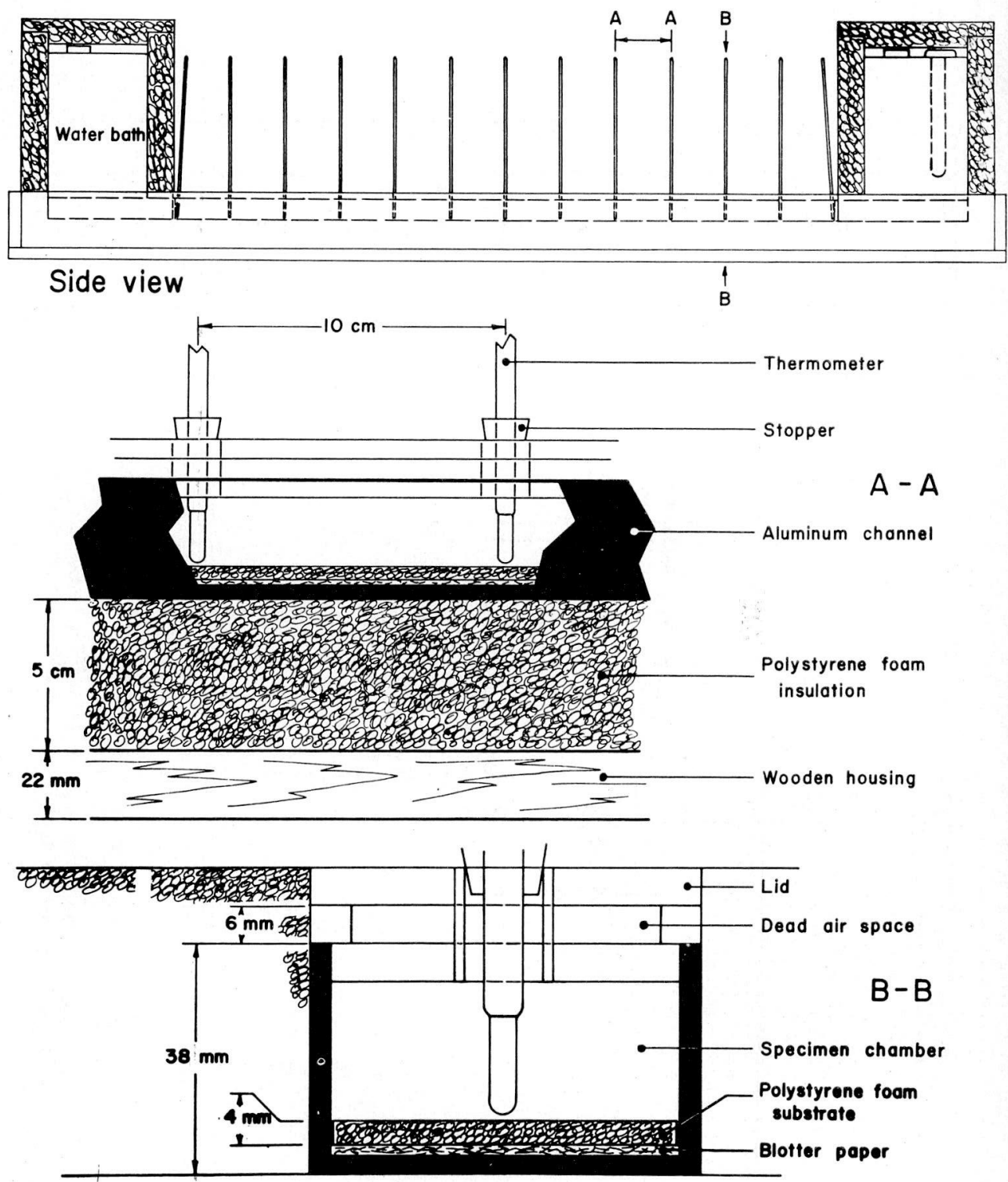


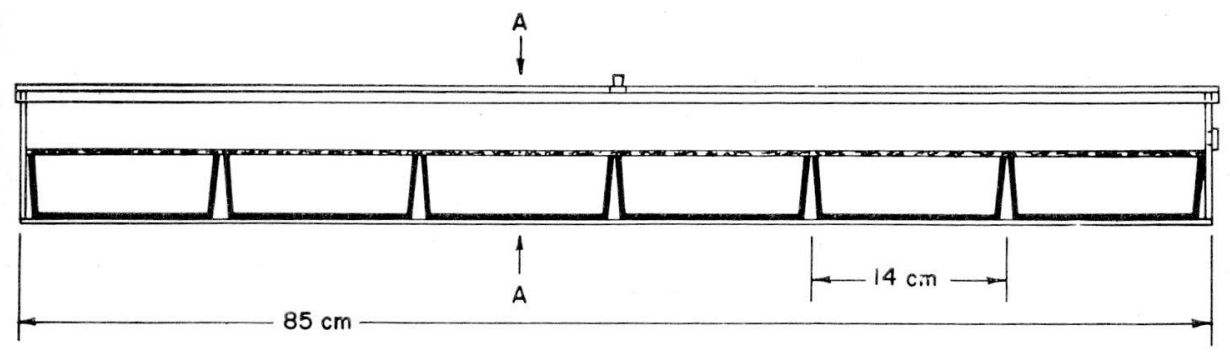

\section{Side view}

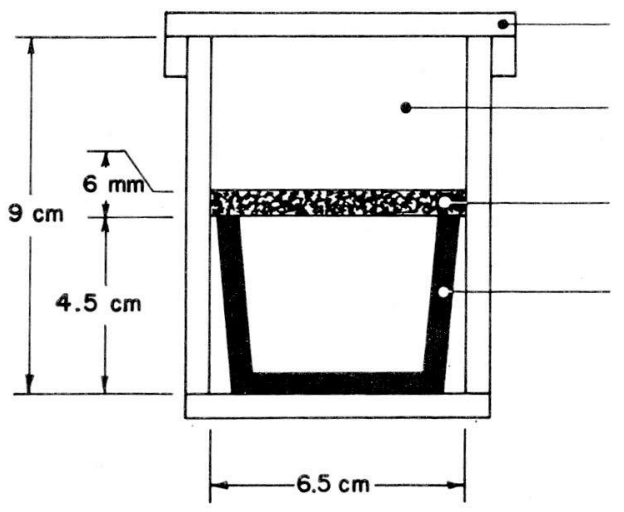

Lid

Specimen chamber

Porous substrate of hardened polyethylene chips

Solution container

$A-A$ 


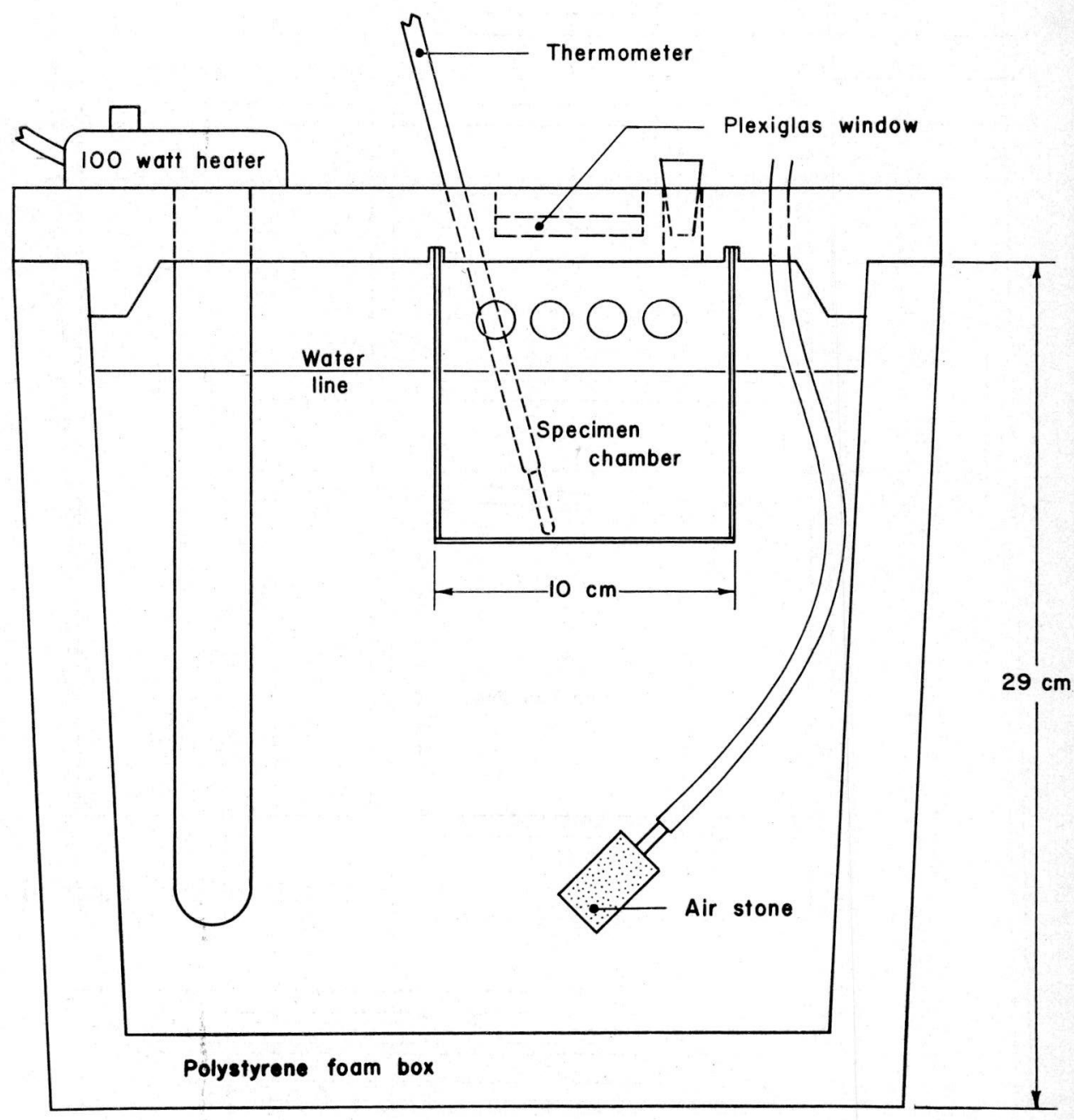



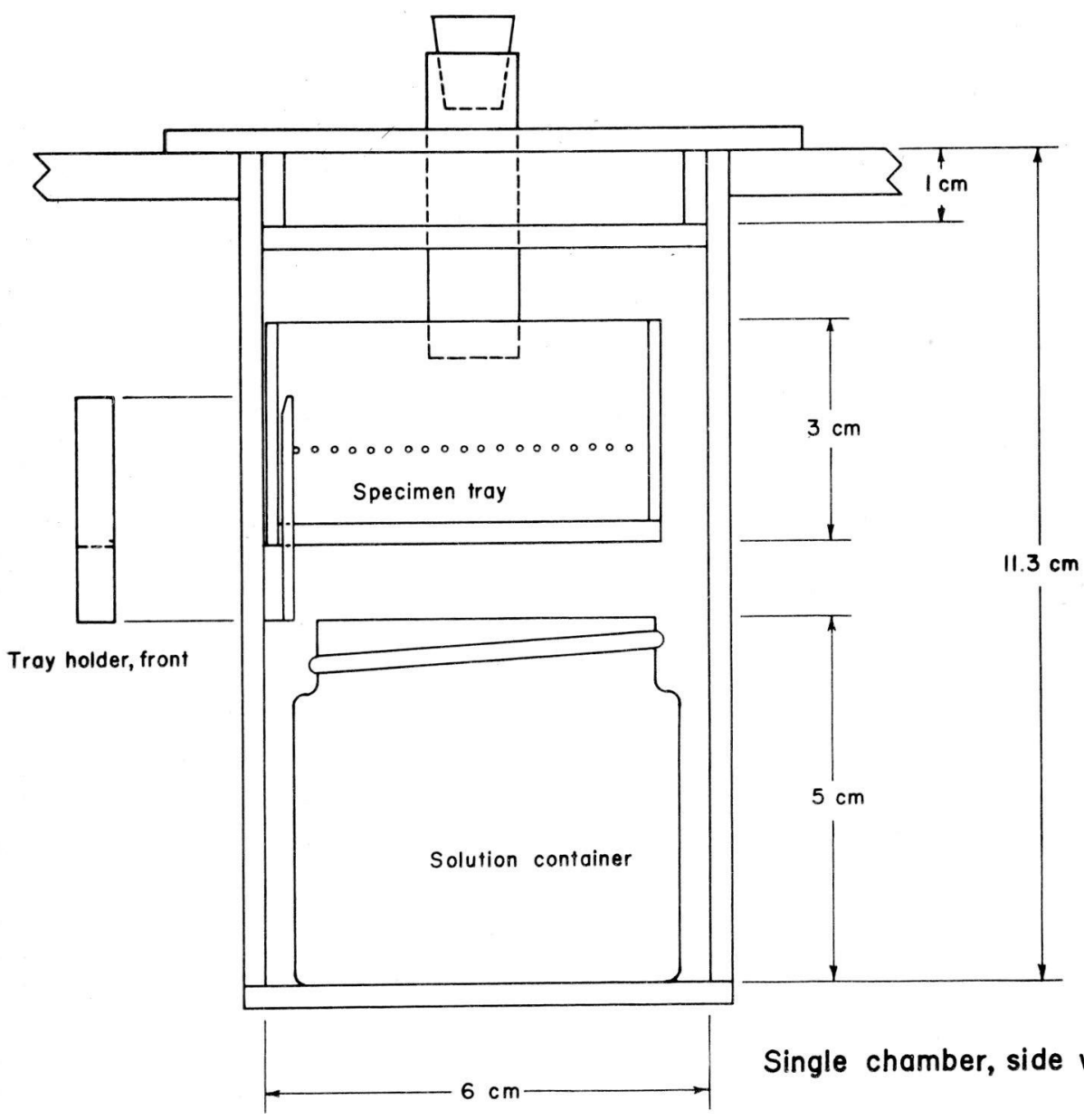

Single chamber, side view

Chamber unit

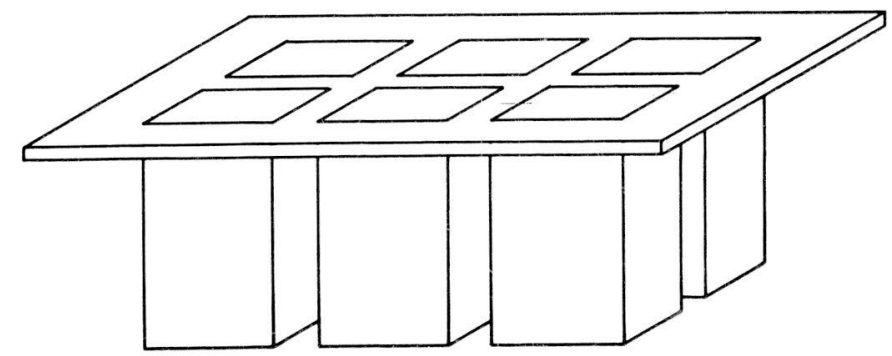


Graph I. Control for Experiment I

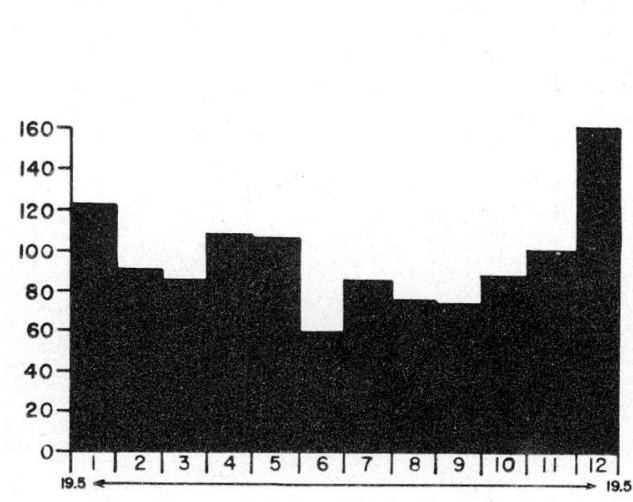

Graph 3. Control for Experiment 2
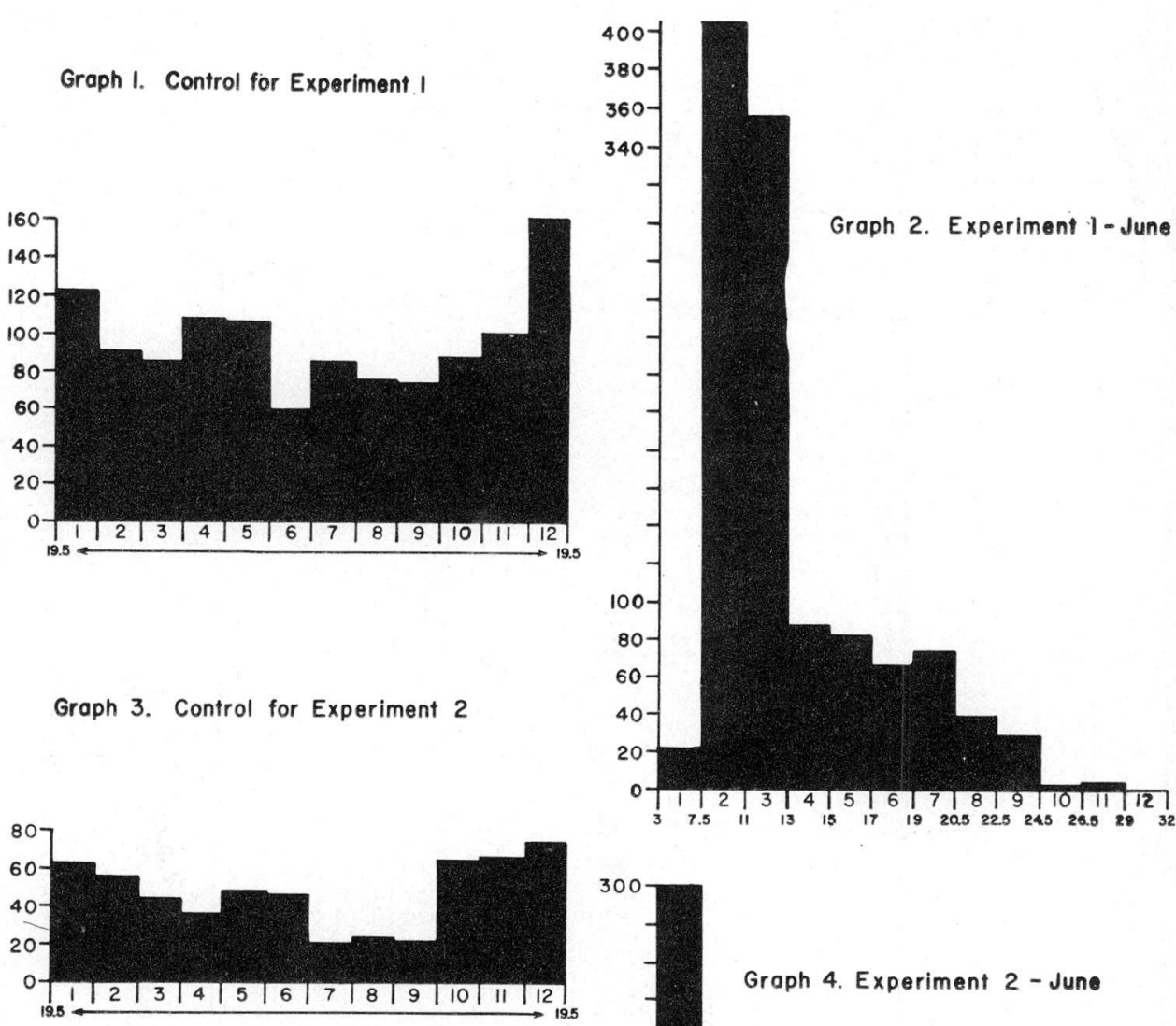

Graph 5. Experiment 3-December

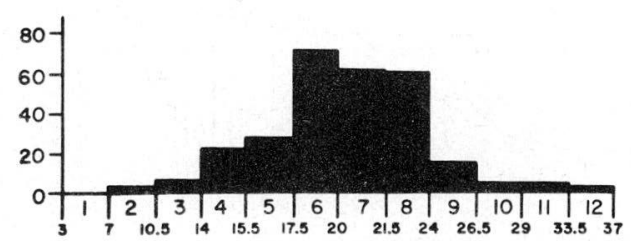

Graph 4. Experiment 2 - June 